\title{
Simulation to Flight Test for a UAV Controls Testbed
}

\author{
Mark A. Motter ${ }^{*}$ and Michael J. Logan ${ }^{\dagger}$ \\ NASA Langley Research Center, Hampton, Virginia, 23681 \\ Michael L. French ${ }^{\ddagger}$ \\ Aviation Applied Technology Directorate, Fort Eustis, Virginia, 23604 \\ and \\ Nelson M. Guerreiro ${ }^{\S}$ \\ National Institute of Aerospace, Hampton, VA 23666
}

\begin{abstract}
The NASA Flying Controls Testbed (FLiC) is a relatively small and inexpensive unmanned aerial vehicle developed specifically to test highly experimental flight control approaches. The most recent version of the FLiC is configured with 16 independent aileron segments, supports the implementation of $\mathrm{C}$-coded experimental controllers, and is capable of fully autonomous flight from takeoff roll to landing, including flight test maneuvers. The test vehicle is basically a modified Army target drone, AN/FQM-117B, developed as part of a collaboration between the Aviation Applied Technology Directorate (AATD) at Fort Eustis, Virginia and NASA Langley Research Center. Several vehicles have been constructed and collectively have flown over 600 successful test flights, including a fully autonomous demonstration at the Association of Unmanned Vehicle Systems International (AUVSI) UAV Demo 2005. Simulations based on wind tunnel data are being used to further develop advanced controllers for implementation and flight test.
\end{abstract}

\section{Nomenclature}

$\begin{array}{ll}\text { AATD } & =\text { Applied Aviation Technology Directorate, Fort Eustis, Virginia } \\ \text { LaRC } & =\text { NASA Langley Research Center, Hampton, Virginia } \\ \text { RCMAT } & =\text { radio controlled miniature aerial target } \\ \text { GPS } & =\text { global positioning system } \\ \text { FLiC } & =\text { Flying Controls Testbed } \\ S O M & =\text { Self Organizing Map } \\ U A V & =\text { unmanned aerial vehicle } \\ M E M S & =\text { Micro-Electro-Mechanical Systems }\end{array}$

\section{Disclaimer}

Reference herein to any specific commercial products, process, or service by trade name, trademark, manufacturer, or otherwise, does not necessarily constitute or imply its endorsement, recommendation, or favoring by the United States Government. The views and opinions of authors expressed herein do not necessarily state or reflect those of the United States Government, and shall not be used for advertising or product endorsement purposes.

\footnotetext{
* Controls Research Engineer, Electronic Systems Branch, Mail Stop 488, Member, AIAA, Senior Member IEEE.

${ }^{\dagger}$ Head, Small Unmanned Aerial Vehicle Laboratory (SUAVELab), MS238, Member AIAA.

‡ Aerospace Engineer, Systems Integration Division, 401 Lee Blvd., President, Hampton Roads AUVSI chapter.

${ }^{\S}$ Graduate Research Associate, NIA/University of Maryland, 100 Exploration Way, Member, AIAA.
} 


\section{Introduction}

$\mathrm{T}$ He project and resulting flight tests described herein are primarily motivated by the desire to conceive, develop, implement, and flight test highly experimental and perhaps even controversial flight control technologies in a relatively low cost and low risk platform. Simulations provide a useful development tool but the focus here is to develop a testbed to demonstrate these control approaches in actual flight. For example, one candidate control approach being considered is a multiple-model controller with dynamic models based on Kohonen's self organizing map (SOM) ${ }^{1}$. The self organizing map embodies a computational method that emulates the long term modulation of lateral inhibitory feedback among neurons during development. The result, a topologically ordered array or lattice of feature detectors, has been shown to provide the basis for modeling highly nonlinear dynamic systems ${ }^{2}$. Some initial experimental work, as well as simulation studies for flight control applications have been reported recently ${ }^{3}$.

A proposal was submitted in June 2002 and consequently accepted by the NASA Langley Creativity and Innovation (C\&I) initiative to develop such a test platform. The initial goal of the project was to develop a small test platform controlled by a commercially available autopilot capable of stabilizing, navigating and recording flight data for a small aerial vehicle in the $2-5 \mathrm{~kg}$ range, obviously unmanned and at least initially, remotely piloted. Concurrently, the Applied Aviation Technology Directorate (AATD) at Fort Eustis expressed a desire to

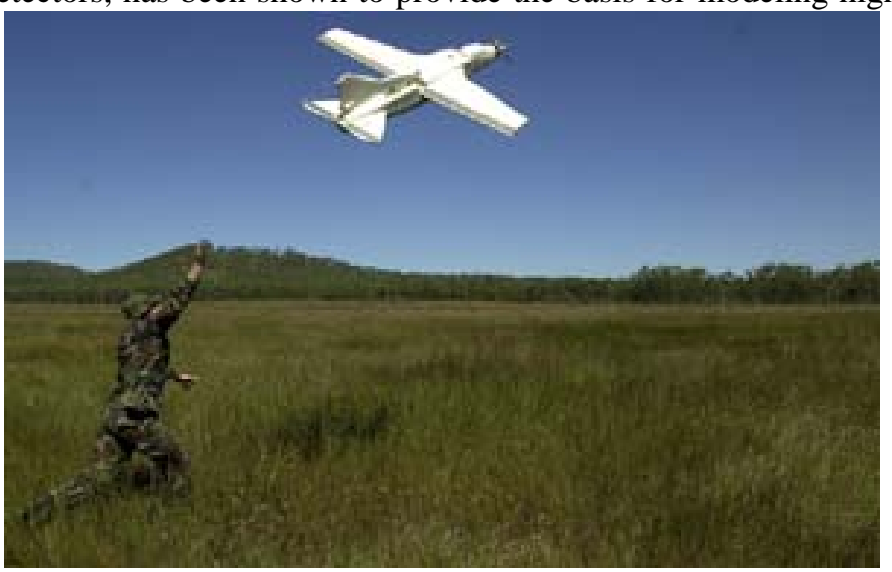

Figure 1. Typical hand launching of AN/FQM-117B collaborate on the development of a small UAV based on the availability of surplus target drones, AN/FQM-117B, referred to generically as a radio controlled miniature aerial target (RCMAT). These planes are roughly a 1/9 scale
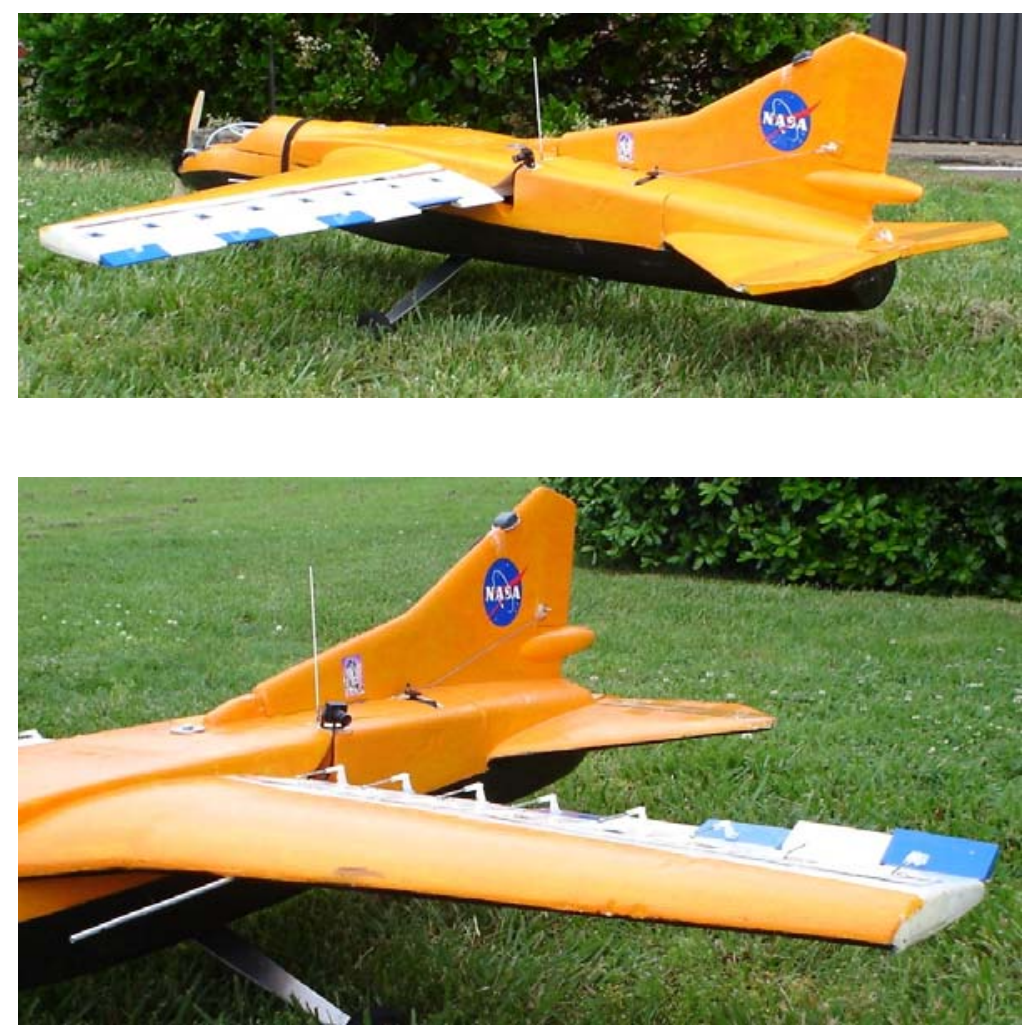

Figure 2. FLiC configured with 16 aileron segments version of a MiG-27, constructed almost entirely of styrofoam, $1.7 \mathrm{~m}$ wingspan, $1.87 \mathrm{~m}$ length, powered by a 9.83 cc, 1.42 $\mathrm{kW}$ glow fuel engine, with a total vehicle weight of approximately $3.63 \mathrm{~kg}$. AATD provided several RCMATs for initial outfitting of standard radio control gear to assess the suitability of these for flight test purposes. The first flight of the most basically equipped version of the FLiC was hand launched on August 2, 2002. A typical hand launch is depicted in Figure 1.

After some modest initial modifications, including landing gear and rudder, it was determined that these planes would be ideal to pursue the goals of the project. Consequently, work began in earnest to install a COTS autopilot, a Micropilot $^{\mathrm{TM}}$ MP2000, into one of the styrofoam MiGs in September 2002. The MP2000 provides stabilization using MEMS technology rate gyros, airspeed and altitude control with pressure measurements, navigation with a GPS receiver and utilizes an ultrasonic sensor for AGL measurements used during auto takeoff and landing..

In the Fall of 2003, an upgraded version 
of the autopilot, the Micropilot MP2028g, was installed. The latest model of the Micropilot, the 2128g, is currently under test.

The UAV Backup Switch, a fully independent mechanism to assert manual RC control or engage the failsafe configuration upon loss of a watchdog signal from the autopilot, was developed by another industry partner, ElectroDynamics. A recent photo of the FLiC configured with sixteen aileron segments is shown in Figure 2. This configuration, using the MP2028g autopilot and UAV Backup Switch, was flown at the AUVSI UAV Demo 2005, June $27^{\text {th }}$, 2005, at Webster Field, MD.

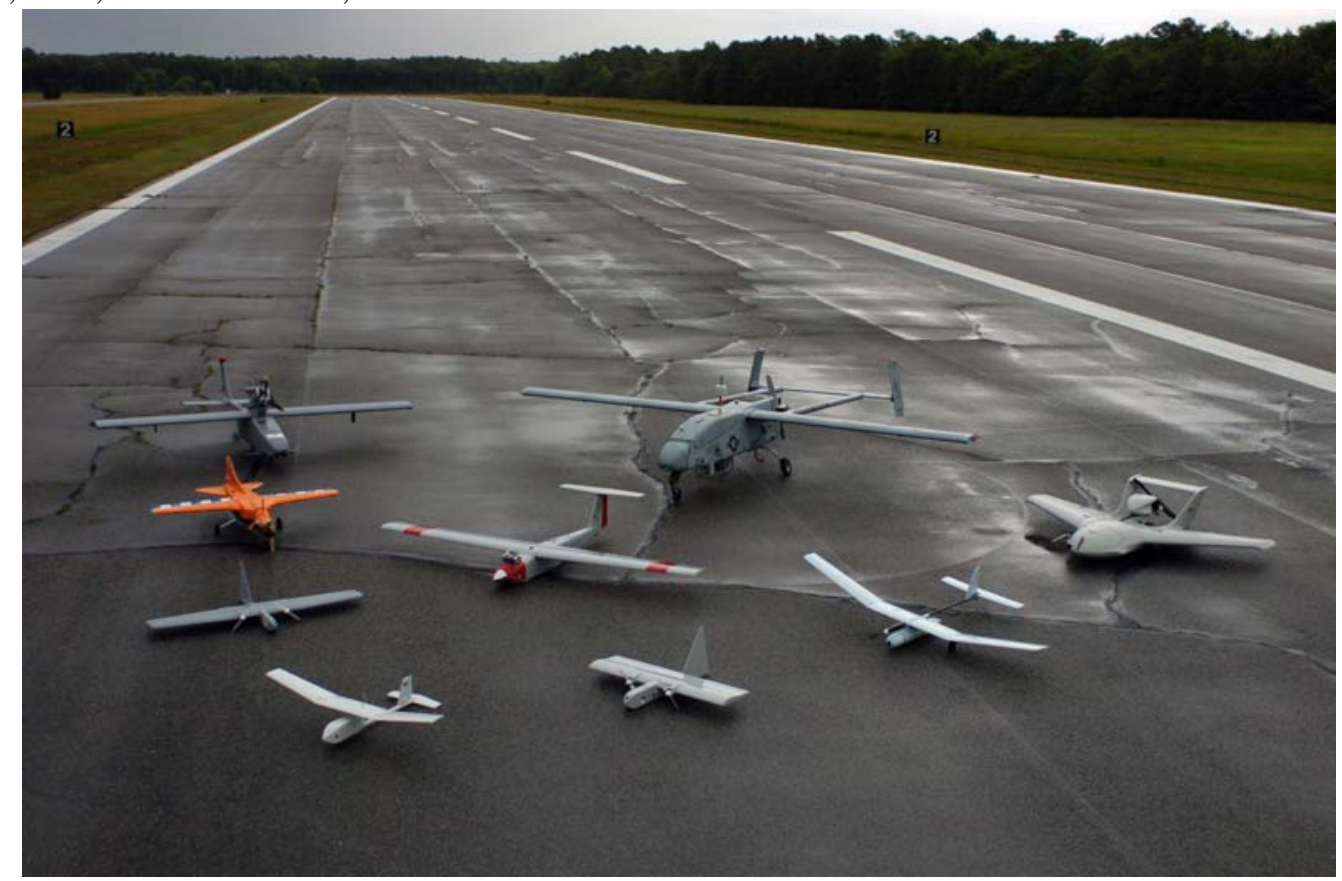

Figure 3. FLiC (orange) with other participants on the runway prior to UAV Demo 2005

\section{Wind Tunnel Tests and Simulation Based Studies}

An FQM-117B drone was modified for wind tunnel testing in NASA Langley's 12-foot Low Speed Tunnel. These wind tunnel test platform allowed for the testing of several wing configurations using the actual flight article, such that a baseline reference of data could be obtained. Among all the configurations, a total of 275 static wind tunnel test runs were performed.

Wing configurations included: full-span ailerons, each aileron surface encompassed one entire half wingspan; conventional ailerons and flaps, each aileron surface accounted for one quarter wingspan, as did each flap surface; and segmented trailing edge flaps, with each aileron segment independently controlled.

The wind tunnel experiments were conducted at an average tunnel dynamic pressure of $2.95 \mathrm{lb} / \mathrm{ft}^{2}$. This correlates to a flow velocity of approximately 30 knots at sea level density. The typical airspeeds of the aircraft in question range from about 30 knots to 70 knots. A target airspeed of 45 knots was chosen as a reference for model development and data collection. This airspeed translates to a required lift coefficient of approximately 0.45 at an angle of attack of about 2 degrees.

The large number of control flaps on the FLiC present a challenge in determining how to model the influence of each surface. Previous research on an aircraft with a similar control flap arrangement indicated that linear superposition could be used to model the total influence on the aircraft dynamics. ${ }^{4}$ In Guerreiro et al. ${ }^{5}$, influence functions are developed and implemented in simulation, using linear superposition, to create the overall system dynamics.

In Shin et al. ${ }^{6}$, simulation model was constructed using Matlab/Simulink implementing the FLiC preliminary configuration data, mass property and static wind tunnel data which covers angles of attack from -6 to 20 degrees and sideslip angles from -16 to 16 degrees, along with the assumed dynamic damping derivatives: $C_{m q}=-1.0$, $C_{l p}=-0.25, \quad C_{n r}=-0.1, C_{m \dot{\alpha}}=0$. The aircraft trim conditions are: $\mathrm{V}_{\mathrm{T}}=31.0 \mathrm{~m} / \mathrm{s}, h_{\mathrm{T}}=122.0 \mathrm{~m}, \alpha_{\mathrm{T}}=-2.816^{\circ}$, and 
$\beta_{\mathrm{T}}=-0.541^{\circ}$. The trimmed throttle set is 0.44 and is held constant. All aerodynamic control deflections range between -25 to 25 degrees with rate limits of $\pm 120 \mathrm{deg} / \mathrm{sec}$. All simulations begin from the trim condition.

That simulation study develops two NN-based adaptive flight controls that have been successfully utilized for a variety of aerospace applications, incorporating recent advances in the area of state/output feedback and adaptation under saturated control conditions. One approach is based on a two-stage dynamic inversion with approximate feedback linearization and synthesis of a fixed-gain linear compensator, and the other approach is a command augmentation system based dynamic inversion control, while both incorporating neural networks as adaptive elements to compensate for the modeling errors, unmodeled dynamic characteristics of the plant. The effects of control saturation are also directly accounted for in the design of the adaptive controller through pseudo-control hedging $(\mathrm{PCH})$.

\section{Flight Test Demo}

On June $27^{\text {th }}$, 2005, the FLiC performed a fully autonomous flight test demo at the Association for Unmanned Systems International (AUVSI) UAV Demo 2005, held at Naval Auxiliary Landing Field, Webster Field, MD. The entire demo flight was under control of the on board autopilot and Ground Control Station (GCS), with no manual input at any time. The scripted flight plan was executed in a similar fashion during the rehearsal flights held the two previous days. The flight plan included:

1) Auto Takeoff, climb to 400 feet, $55 \mathrm{kts}$

2) Pitch Test 1: 0-5 degrees, climb to 800'

3) Pitch Test $2: 0,5,10,15,0,-5,-10,-15,+15$

4) Independent aileron segment demos initiated from GCS

5) Altitude and airspeed changes from GCS

6) Descend to 400', simulated approach and go-around at 200'

7) Set up approach to auto landing

8) Auto landing
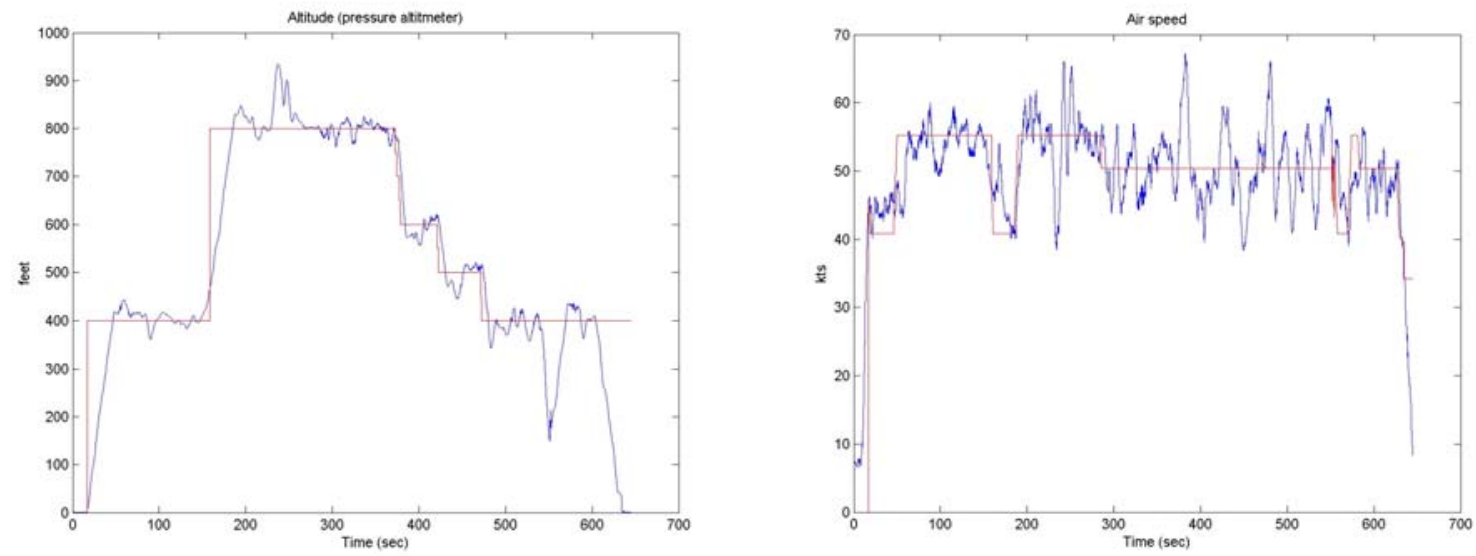

Figure 4. Altitude and airspeed during flight test demo 


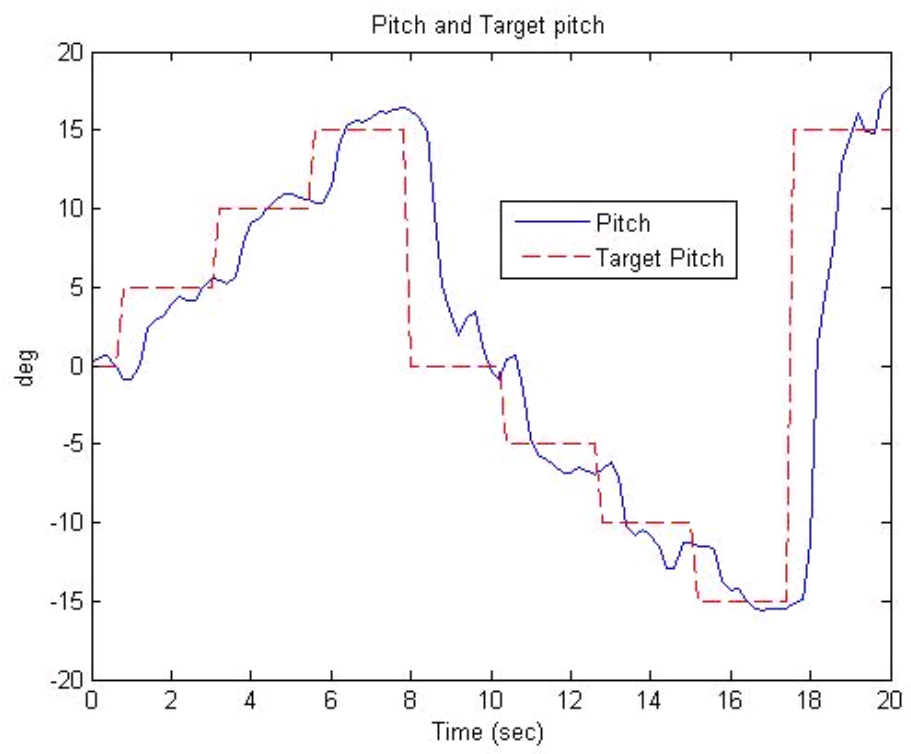

Figure 5. Stepped Pitch Test during flight test demo

Figure 4 shows the altitude and airspeed commanded and the resulting responses, while Figure 5 shows the results of the stepped pitch tests.

\section{Conclusion}

The initial goal of the Flying Control Testbed (FLiC), to develop a small unmanned aerial vehicle controlled by a commercially available autopilot, has been achieved and demonstrated. The continuing research plans for the vehicle are to implement experimental control approaches such as self-organizing-map (SOM) based multiple model controllers as well as supporting the development of other adaptive control approaches based on simulations derived from wind tunnel data and other measurements. It is anticipated that parameter identification based on flight test data will be used to refine the simulations and subsequent controller implementations.

\section{References}

${ }^{1}$ Kohonen, T., “The self-organizing map,” Proceedings of the IEEE, Vol. 78, No. 9, 1990.

${ }^{2}$ Principe, J.C., Wang, L., Motter, M.A , "Local Dynamic Modeling with Self-Organizing Maps and Applications to Nonlinear System Identification and Control,” Principe, J.C., Wang, L., Motter, M.A., Proceedings of the IEEE, Vol. 86, No. 11, November 1990.

${ }^{3}$ Cho, J., Principe, J.C., Erdogmus, D., and Motter, M. A., "Modeling and Inverse Controller Design for an Unmanned Aerial Vehicle Based on the Self-Organizing Map,” IEEE Transactions on Neural Networks, Vol. 17, No. 2, March 2006, pp. 445-460.

${ }^{4}$ Abdulrahim, M., and Lind, R., "Investigating Segmented Trailing-Edge Surfaces for Full Authority Control of a UAV," AIAA Atmospheric Flight Mechanics Conference, AIAA-2003-5312, Austin, TX, August 2003

${ }^{5}$ Guerreiro, N.M., Hubbard, J.E., and Motter, M.A.., "Non-linear controls influence functions in an aircraft dynamics simulator," SPIE International Symposia on Smart Structures \& Materials/NDE, San Diego,CA, February 2006

${ }^{6}$ Shin, Y., Calise, A.J.., and Motter, M.A.., “Adaptive Autopilot Designs for an Unmanned Aerial Vehicle,” AIAA Guidance, Navigation and Control Conference, AIAA-2003-5312, San Francisco, CA, August 2005 